\title{
GAMBARAN TAHAP MATURASI TULANG PHALANX JARI KE- TIGA DAN TULANG SERVIKAL PADA PASIEN ORTODONSIA UMUR 10-16 TAHUN (Laporan Penelitian)
}

\author{
Riandri Chaera Runizar*, Retno Widayati**, Permana Irmansyah Masbirin** \\ *PPDGS Ortodonsia Facultas Kedokteran Gigi Universitas Indonesia \\ **Staf Pengajar Departemen Ortodonsia Fakultas Kedokteran Gigi Universtas Indonesia
}

\begin{abstract}
Keywords:
Growth and development; Skeletal maturity; Middle phalanx of the third finger; Cervical vertebrae
\end{abstract}

\begin{abstract}
In orthodontics, it is important to assess the skeletal maturity in order to make accurate diagnosis and to plan for appropriate treatment. Evaluation of the skeletal maturity through developmental stages of middle phalanx of the third finger (MP3) and cervical vertebrae $(\mathrm{CV})$ could help in predicting growth acceleration. The methods to evaluate maturity are being developed in order to obtain simple, low radiation and low cost tools for this purpose. The objectives of this study were to identify (1) MP3 maturation stages, (2) CV maturation stages, and (3) agreement between MP3 and CV of 10-16 year-old orthodontic patients. Skeletal maturity of 72 subjects from the Orthodontic Clinic at the Dental Faculty of University of Indonesia was assessed by classifying developmental stages of MP3 as seen in a periapical film and CV as seen on a lateral cephalometric film. MP3 was classified into six stages according to Rajagopal and Kansal method. CV was also classified into six stages as described by Cervical Vertebrae Maturation Index (CVMI). The results showed that (1) at the same chronological age, MP3 and CV maturation stages could vary and the stages follow a gradual chronologic progression; (2) large variation of MP3 maturation stages was found in 12 year-old females (MP3-FG to MP3-I) and in 13-14 year-old males (MP3-FG to MP3-HI), (3) large variation of $\mathrm{CV}$ maturation stages was found in 12 year-old females (CVMI 2 to 5) and in 12-13 year-old males (CVMI 1, 2, 3 and 5), and (4) an agreement of $70.8 \%$ between MP3 and CV maturation stages was found in 10-16 year-old orthodontic patients. This study concluded that besides CVMI, the maturation stages of MP3 could be used as an alternative method to assess the skeletal maturity in orthodontics.
\end{abstract}




\section{Pendahuluan}

Informasi perawatan ortodonsia saat ini telah tersebar ke masyarakat terutama di daerah perkotaan. Hal ini merupakan dampak positif dari perkembangan pesat teknologi informasi dansemakin giatnya para penyuluh kesehatan gigi memberikan informasi seputar ortodonsia. Kini masyarakat memahami bahwa susunan gigi geligi yang tidak teratur akan mengganggu fungsi pengunyahan dan estetika wajah. Mereka berharap kelainan ini dapat diperbaiki lebih dini. Hal ini terlihat dari meningkatnya kunjungan anak-anak dengan kasus anomali dentofasial ke dokter gigi atau ortodontis. Untuk merencanakan dan mencapai hasil perawatan yang baik diperlukan diagnosis yang menggambarkan kelainan struktur dental dan skeletal termasuk potensi tumbuh kembang pasien. Banyak ahli berpendapat bahwa masa yang sangat menguntungkan untuk perawatan ortopedi dentofasial adalah pada masa percepatan pertumbuhan, karena itu para ortodontis memerlukan suatu metode untuk memprediksi periode ini. ${ }^{1,2}$

Berbagai penelitian dilakukan untuk menilai hubungan antara masa percepatan pertumbuhan dengan indikator tumbuh kembang anak seperti umur kronologis, umur fisiologis dengan tinggi dan berat badan, umur dental, maturasi skeletal dan karakteristik seks sekunder. Hasil beberapa penelitian menyimpulkan bahwa umur kronologis kurang akurat untuk mengevaluasi tumbuh kembang anak, karena pada tahap tumbuh kembang yang sama umur kronologisnya sangat bervariasi. ${ }^{1-6}$ Tinggi badan adalah salah satu parameter untuk mengukur pertumbuhan, tetapi parameter ini juga tidak dapat memprediksi potensi pertumbuhan di masa datang atau memprediksi sisa pertumbuhan yang masih ada. ${ }^{2,3}$ Prediksi potensi pertumbuhan ternyata dapat diketahui melalui tahap maturasi skeletal tulang karpal. Bahkan penelitian Hunter (1966), Bergersen (1972) dan Fishman (1977) menunjukkan hubungan yang kuat antara maturasi tulang karpal dengan pertambahan tinggi badan dan pertumbuhan maksila maupun mandibula., ${ }^{1,5}$

Selanjutnya penelitian Hassel dan Farman
(1995), Kucukkeles dan kawan-kawan (1999), Gandini dan kawan-kawan (2006) membuktikan adanya hubungan yang kuat antara perubahan bentuk dan densitas tulang servikal dengan tahap maturasi tulang karpal. ${ }^{7-9}$ Untuk mempermudah para ortodontis untuk mengevaluasi tahap tumbuh kembang anak perlu diteliti gambaran tulang servikal pada foto sefalometri.

Untuk mengurangi radiasi dan biaya pembuatan foto karpal, para peneliti menyederhanakan metode pembuatan dan analisis tulang karpal tanpa mengurangi ketepatan hasil. Abdel Kader (1998), Rajagopal dan Kansal (2002), meneliti kehandalan foto periapeks untuk merekam tahap perkembangan tulang phalanx tengah jari ke tiga (MP3) sebagai indikator maturasi seperti yang dikembangkan oleh Hagg dan Taranger (1980). Mereka membandingkan tahap perubahan MP3 dengan tahap perubahan tulang servikal. Metode ini mengurangi paparan radiasi 5 kali lebih rendah dengan biaya lebih murah. ${ }^{10,13}$ Hagg dan Taranger menyatakan bahwa MP3 dapat dipakai sebagai indikator maturasi karena pusat ossifikasi tulang ini tumbuh mengikuti proses percepatan pertumbuhan. Para peneliti lain seperti Tanner, Bjork, dan Fishman sebelumnya juga membuktikan MP3 dapat dipakai sebagai indikator maturasi.$^{1-3,6}$

Pertumbuhan dan perkembangan anak sangat bervariasi. ${ }^{14}$ Berdasarkan alasan tersebut maka perlu diketahui gambaran maturasi $M P 3$ dan tulang servikal pada pasien di kinik ortodonsia RSGM-P FKGUI. Jika ternyata pola maturasi MP3 mempunyai kesesuaian dengan pola maturasi tulang servikal, maka tahap perkembangan MP3 pada foto periapikal merupakan salah satu alternatif untuk menilai maturasi skeletal anak.

\section{Bahan dan Cara Kerja}

Seleksi subyek penelitian berlangsung dari Desember 2006 sampai Maret 2007 di Klinik Ortodonti RSGMP FKGUI, diperoleh 72 subyek yang memenuhi kriteria inklusi sebagai berikut: (1) pasien usia tumbuh kembang 10-16 tahun, 
(2) riwayat kesehatan umum baik, (3) tinggi dan berat badan normal (menurut KMS), (4) kualitas sefalogram dan foto periapeks MP3 baik. Kriteria eksklusi adalah sebagai berikut: (1) pasien usia tumbuh kembang 10-16 tahun dengan kelainan mental, (2) pasien memenuhi kriteria inklusi tetapi tidak bersedia ikut dalam penelitian. Pasien yang setuju ikut berpartisipasi menandatangani inform consent. Selanjutnya pada pasien dilakukan anamnesis, pengukuran tinggi dan berat badan, pembuatan foto sefalometri dan periapeks MP3 pada waktu yang sama.

Pembuatan foto sefalometri dan periapeks MP3 dilakukan di Departemen Radiologi RSGMP FKGUI. Foto periapikal MP3 dibuat dengan alat sinar- $x$ dental standar dengan paparan sinar $60 \mathrm{kV}$ dan $7 \mathrm{~mA}$. Film dental standar diletakkan di bawah phalanx tengah jari ke-tiga. Corong sinar $\mathrm{x}$ diletakkan sedekat mungkin dan tegak lurus terhadap phalanx tengah. Waktu paparan 0,25 detik.

Maturasi tulang servikal dievaluasi menurut Cervical Vertebrae Maturation Indices yang dikembangkan oleh Hassel dan Farman seperti berikut ini.

CVMI 1 adalah gambaran foto sefalometri bagian inferior korpus tulang servikal 2,3,4 datar, bagian superior korpus tapered dari posterior ke anterior.

CVMI 2 adalah gambaran foto sefalometri bagian inferior korpus tulang servikal 2,3 cenderung cekung sedangkan bagian inferior korpus tulang servikal 4 masih datar. Korpus tulang servikal 3,4 lebih membentuk persegi empat.

CVMI 3 adalah gambaran foto sefalometri bagian inferior korpus tulang servikal 2,3 tampak cekung. Bagian inferior korpus tulang servikal 4 cenderung cekung. Korpus tulang servikal 3,4 berbentuk segi empat.

CVMI 4 adalah gambaran foto sefalometri bagian inferior korpus tulang servikal 2,3,4 tampak cekung. Korpus tulang servikal 3,4 hampir membentuk bujursangkar.
CVMI 5 adalah gambaran foto sefalometri bagian inferior korpus tulang servikal 2,3,4 kecekungan semakin nyata. Korpus tulang servikal 3,4 berbentuk bujur sangkar.

CVMI 6 adalah gambaran foto sefalometri bagian inferior korpus tulang servikal 2,3,4 kecekungan semakin dalam. Tinggi korpus tulang servikal 3,4 lebih daripada lebar (Gambar $1)$.

Maturasi phalanx tengah jari ke-tiga (MP3) adalah maturasi tulang MP3 menurut metode Hagg dan Taranger modifikasi Rajagopal dan Kansal sebagai berikut.

$M P 3-F$ adalah gambaran MP3 pada foto periapeks terlihat epifisis selebar metafisis, tidak ada garis bergelombang pada metafisis, radiolucent gap antara epifisis dan metafisis lebar.

$M P 3-F G$ adalah gambaran $M P 3$ pada foto periapeks terlihat epifisis selebar metafisis, batas medial dan/atau lateral epifisis membentuk garis pembatas yang tegak lurus terhadap batas distal, metafisis mulai sedikit bergelombang, radiolucent gap antara epifisis dan metafisis lebar.

$M P 3-G$ adalah gambaran MP3 pada foto periapeks terlihat sisi epifisis menebal dan membentuk capping ke arah metafisis pada satu atau dua sisi, garis bergelombang semakin nyata dan tampak lebih tajam, radiolucent gap antara epifisis dan metafisis berkurang.

MP3-H adalah gambaran MP3 pada foto periapeks terlihat epifisis dan diafisis mulai berfusi, satu atau kedua sisi epifisis membentuk sudut tumpul terhadap batas distal.

MP3-HI adalah gambaran MP3 pada foto periapeks terlihat permukaan superior epifisis tampak cekung, permukaan metafisis cembung hampir sesuai dengan kecekungan epifisis.

MP3-I adalah gambaran MP3 pada foto periapeks terlihat epifisis dan metafisis berfusi sempurna, tidak ada radiolucent gap antara epifisis dan diafisis, garis epifiseal radiopak dan padat bersatu dengan bagian proksimal phalanx tengah (Gambar 1). 

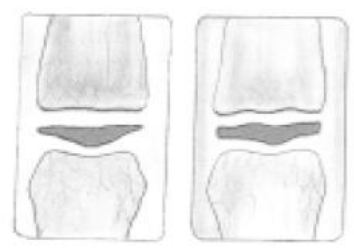

MPJ - F STAGE

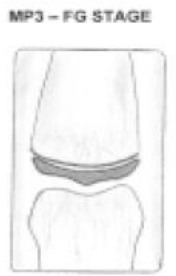

MPJ - G STAGE

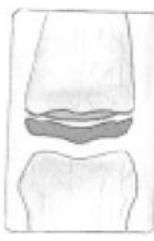

A MPS-H STAGE

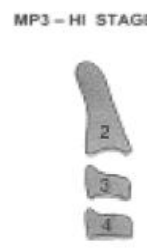

cvNen-1

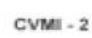

B CVMI-4

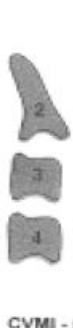

CVMI - 5
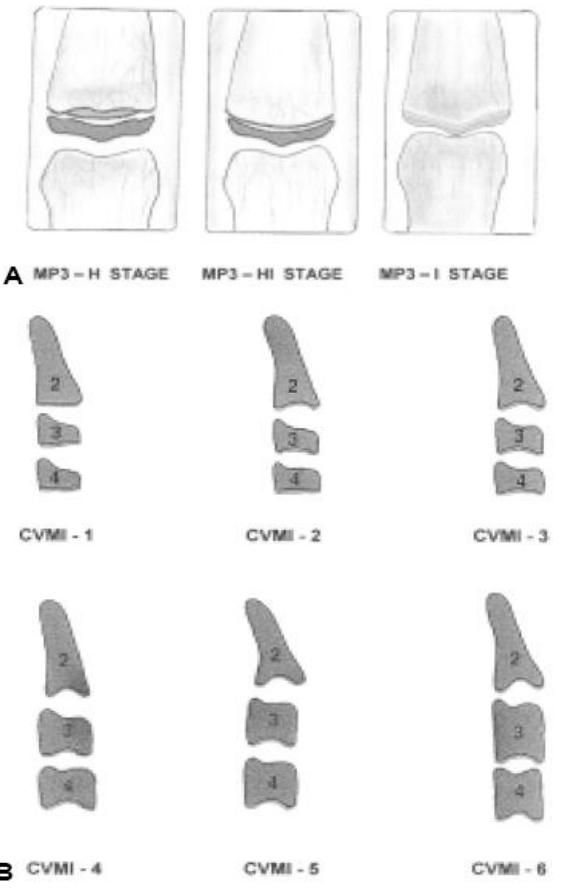

Gambar 1. A. Enam tahap perkembangan MP3. B. Enam tahap perkembangan tulang servikal. ${ }^{10}$
Hasil

Subyek penelitian yang terkumpul sebanyak 72 anak dalam rentang umur 10-16 tahun yang terdiri dari 47 ( 65,3\%) perempuan dan 25 $(34,7 \%)$ laki-laki. Rata-rata usia subyek adalah 12,58 tahun.

\section{Kalibrasi interoperator di lakukan dengan cara}

Sepuluh foto diinterpretasikan oleh dua operator. Interpretasi $C V M I$ operator A sesuai dengan operator B pada $90 \%$ kasus. Interpretasi MP3 operator A sesuai dengan operator B pada $80 \%$ kasus. Kalibrasi intraoperator dilakukan dengan menginterpretasikan 20 foto dalam interval waktu 2 minggu. Hasil interpretasi CVMI sama pada 85\% kasus dan MP3 sama pada $90 \%$ kasus.

Gambaran tahap maturasi $M P 3$ dan tulang servikal pada subyek anak laki-laki dan perempuan menurut kelompok umur dapat dilihat pada Tabel 1 dan 2 .

\section{Kesesuaian Tahap Maturasi Mp3 terhadap Tulang Serv}

Sebaran tahap maturasi MP3 terhadap tulang servikal dan tahap maturasi disajikan pada Tabel 5. Jika jumlah dari masing masing tahap maturasi tulang servikal yang sesuai dengan masing-masing tahap maturasi $M P 3$ (jumlah angka dalam sel biru $=51$ ) dibagi jumlah keseluruhan subyek (72) kemudian dikalikan seratus persen maka hasilnya adalah $70,8 \%$.

Tabel 1. Tahap maturasi $M P 3$ dan tulang servikal menurut kelompok umur subyek anak perempuan

\begin{tabular}{lll}
\hline Umur (tahun) & $M P 3$ F s/d $I$ & CVMI I-6 \\
\hline 10 & F, FG, G, H & $1,2,4$ \\
11 & FG, G, H & $2,3,4$ \\
12 & FG, G, H, HI, I & $2,3,4,5$ \\
13 & H, HI, I & $4,5,6$ \\
14 & H, HI, I & $4,5,6$ \\
15 & I & 5,6 \\
16 & I & 6 \\
\hline
\end{tabular}


Gambaran Tahap Maturasi Tulang

Tabel 2. Tahap maturasi $M P 3$ dan tulang servikal menurut kelompok umur subyek anak laki-laki

\begin{tabular}{crr}
\hline Umur (tahun) & \multicolumn{2}{c}{ CVMI 1-6 } \\
\hline 10 & F $/ \mathrm{d} I$ & 1,2 \\
11 & $\mathrm{~F}, \mathrm{FG}$ & 2,3 \\
12 & $\mathrm{FG}, \mathrm{G}$ & $1,2,3$ \\
13 & $\mathrm{FG}, \mathrm{G}, \mathrm{HI}$ & $2,3,5$ \\
14 & $\mathrm{G}, \mathrm{H}, \mathrm{HI}$ & 2,4 \\
15 & $\mathrm{H}, \mathrm{HI}$ & 5,6 \\
16 & $\mathrm{G}, \mathrm{I}$ & 4,5 \\
\hline
\end{tabular}

Hal ini berarti $70,8 \%$ tahap maturasi tulang servikal sesuai dengan tahap maturasi MP3. Jika jumlah dari tahap maturasi MP3 yang satu tahap lebih tinggi dari tahap maturasi tulang servikal (jumlah angka dalam sel hijau $=14$ ) dibagi jumlah keseluruhan subyek (72) kemudian dikalikan seratus persen, hasilnya adalah 19,4\%. Jika jumlah dari tahap maturasi MP3 yang satu tahap lebih rendah dari tahap maturasi tulang servikal (jumlah angka dalam sel merah jambu =7) dibagi jumlah keseluruhan subyek (72) kemudian dikalikan seratus persen, hasilnya adalah $9,7 \%$.

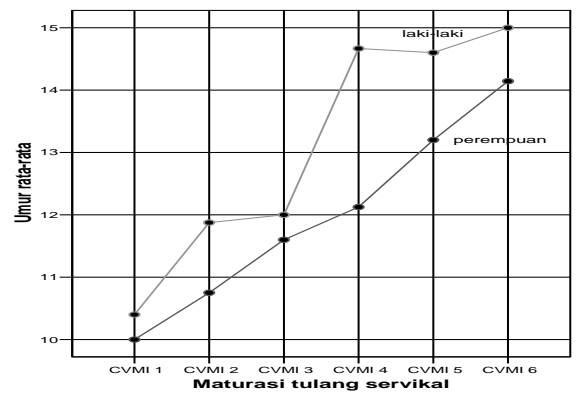

Gambar 2. Grafik maturasi tulang servikal menurut umur pada laki-laki dan perempuan.

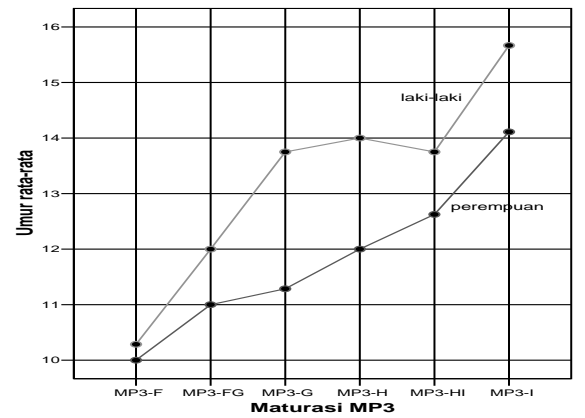

Gambar 3. Grafik maturasi $M P 3$ menurut umur pada laki-laki dan perempuan.
Pada penelitian ini perempuan $(65,3 \%)$ lebih banyak daripada laki-laki $(34,7 \%)$ karena populasi penelitian diambil di Klinik Ortodonti RSGM-P FKGUI yang persentase pasien perempuan lebih tinggi dari laki-laki. Perbedaan ini diharapkan tidak mempengaruhi hasil karena menurut Bjork (1967) pada semua tahap maturasi perbedaan gender kecil dan tidak signifikan. ${ }^{6}$ Rentang umur subyek penelitian adalah umur 10-16 tahun, dan semua kelompok umur terwakili.

Tinjauan hasil penelitian menurut umur dan gender, tampak variasi yang besar dari maturasi MP3 dan tulang servikal anak laki-laki dan perempuan pada umur yang sama. Pada anak perempuan umur 10 tahun variasi maturasi MP3 berkisar antara tahap $\mathrm{F}$ (inisiasi percepatan pertumbuhan) sampai $\mathrm{H}$ (akhir percepatan pertumbuhan), sedangkan anak laki-laki baru pada tahap F. Pada umur 13 tahun, 4 dari 8 subyek perempuan sudah mencapai tahap MP3$I$ (akhir percepatan pertumbuhan), anak laki-laki belum ada yang mencapai tahap tersebut. Saat mencapai 15 tahun semua subyek perempuan sudah mencapai akhir percepatan pertumbuhan (MP3-I ), anak laki-laki masih ada yang berada pada tahap MP3-HI (Tabel 1 dan 2).

Variasi maturasi skeletal terhadap umur yang terlihat pada hasil penelitian ini sesuai dengan hasil penelitian oleh Hunter (1966), Bergersen (1972), Fishman (1977), Hagg dan Taranger (1982) yang menyatakan bahwa umur kronologis kurang dapat memprediksi maturasi skeletal. ${ }^{1-5}$ 
Tabel 3. Umur kronologis pada tahap maturasi tulang servikal

\begin{tabular}{lrrrrrrr}
\hline \multirow{2}{*}{$\begin{array}{l}\text { Maturasi tulang } \\
\text { servikal }\end{array}$} & \multicolumn{3}{c}{ Perempuan } & \multicolumn{2}{c}{ Laki-laki } & \multirow{2}{*}{$\begin{array}{c}\text { Selisih } \\
\text { umur }\end{array}$} \\
\cline { 2 - 7 } & $\begin{array}{c}\text { Umur } \\
\text { rata-rata }\end{array}$ & $\begin{array}{c}\text { Simpang } \\
\text { baku }\end{array}$ & $\begin{array}{c}\text { Jumlah } \\
\text { subyek }\end{array}$ & $\begin{array}{c}\text { Umur } \\
\text { rata-rata }\end{array}$ & Simpang baku & $\begin{array}{c}\text { Jumlah } \\
\text { subyek }\end{array}$ &, 40 \\
\hline CVMI 1 & 10,00 &, 000 & 2 & 10,40 &, 894 & 5 & 1,13 \\
CVMI 2 & 10,75 &, 886 & 8 & 11,88 & 1,356 & 8 &, 40 \\
CVMI 3 & 11,60 &, 548 & 5 & 12,00 & 1,000 & 3 & 2,54 \\
CVMI 4 & 12,13 & 1,246 & 8 & 14,67 & 1,155 & 3 & 1,40 \\
CVMI 5 & 13,20 & 1,229 & 10 & 14,60 & 1,517 & 5 & 0,86 \\
CVMI 6 & 14,14 & 1,027 & 14 & 15,00 & & 1
\end{tabular}

Tabel 4. Umur kronologis pada tahap maturasi $M P 3$

\begin{tabular}{|c|c|c|c|c|c|c|c|}
\hline \multirow[b]{2}{*}{ Maturasi $M P 3$} & \multicolumn{3}{|c|}{ Perempuan } & \multicolumn{3}{|c|}{ Laki-laki } & \multirow{2}{*}{$\begin{array}{c}\text { Selisih } \\
\text { umur }\end{array}$} \\
\hline & $\begin{array}{c}\text { Umur } \\
\text { rata-rata }\end{array}$ & $\begin{array}{c}\text { Simpang } \\
\text { Baku }\end{array}$ & $\begin{array}{l}\text { Jumlah } \\
\text { subyek }\end{array}$ & $\begin{array}{c}\text { Umur } \\
\text { rata-rata }\end{array}$ & Simpang Baku & $\begin{array}{l}\text { Jumlah } \\
\text { subyek }\end{array}$ & \\
\hline$M P 3-F$ & 10,00 &, 000 & 3 & 10,29 & ,488 & 7 & ,29 \\
\hline$M P 3-F G$ & 11,00 & 1,000 & 5 & 12,00 & ,894 & 6 & 1,00 \\
\hline$M P 3-G$ & 11,29 & ,756 & 7 & 13,75 & 1,708 & 4 & 2,46 \\
\hline$M P 3-H$ & 12,00 & 1,414 & 6 & 14,00 & . & 1 & 2,00 \\
\hline MP3-HI & 12,63 & ,744 & 8 & 13,75 & 957 & 4 & 1,12 \\
\hline$M P 3-I$ & 14,11 & 1,079 & 18 & 15,67 & ,577 & 3 & 1,56 \\
\hline
\end{tabular}

Tabel 5. Sebaran tahap maturasi $M P 3$ dan tulang servikal

Mat. MP3

Mat. Servikal
Maturasi $M P 3$

MP3-G MP3-H MP3-HI

MP3-I

\begin{tabular}{|c|c|c|c|c|c|c|c|c|}
\hline \multirow{6}{*}{$\begin{array}{l}\text { Maturasi } \\
\text { tulang servikal }\end{array}$} & CVMI 1 & 6 & 1 & & & & & 7 \\
\hline & CVMI 2 & 4 & 9 & 3 & & & & 16 \\
\hline & CVMI 3 & & 1 & 6 & 1 & & & 8 \\
\hline & CVMI 4 & & & 2 & 6 & 3 & & 11 \\
\hline & CVMI 5 & & & & & 9 & 6 & 15 \\
\hline & CVMI 6 & & & & & & 15 & 15 \\
\hline Total & & 10 & 11 & 11 & 7 & 12 & 21 & 72 \\
\hline
\end{tabular}

Temuan ini perlu diperhatikan dalam praktek ortodonsia klinis, khususnya dalam merencanakan perawatan pasien diskrepansi skeletal dalam usia tumbuh kembang. Perawatan ortodonti seringkali hanya didasari atas pertimbangan umur kronologis dan umur dental, sedangkan kedua umur tersebut kurang dapat memprediksi tahap perkembangan skeletal anak. Hasil perawatan dengan menggunakan alat ekstraoral atau myofunctional appliance akan lebih optimal jika direncanakan berdasarkan maturasi skeletal. ${ }^{1,2}$

Perlu diperhatikan bahwa tahap maturasi skeletal yang pada penelitian ini diwakili oleh tulang servikal dan MP3 meningkat sesuai dengan bertambahnya umur (Gambar 2 dan 3).
Menurut Fishman (1981) indikator maturasi skeletal mengikuti peningkatan umur secara bertahap sepanjang periode pertumbuhan. Pada Gambar 2 peningkatan tahap maturasi tulang servikal laki-laki tidak sama dengan perempuan karena pada CVMI 2 variasi umur laki-laki sangat besar yaitu dari 10-14 tahun. CVMI 4 muncul hanya pada umur 14 dan 16 tahun. Titik CVMI 5 menurun karena jumlah subyek lebih banyak dari $C V M I 4$ dan rentang umurnya lebih bervariasi dari 13-16 tahun.

Pada Gambar 3, kenaikan grafik dari tahap $M P 3-G$ ke $M P 3-H$ laki-laki tidak tinggi karena $M P 3-H$ hanya diwakili oleh 1 subyek sehingga tidak ada variasi umur. Kemudian dari $M P 3-H$ ke $M P 3-H I$ terjadi penurunan karena variasi 
umur subyek pada tahap ini berkisar antara 1315 tahun.

Tahap percepatan pertumbuhan perempuan pada penelitian ini yaitu CVMI 2/MP3-FG dimulai satu tahun lebih awal daripada laki-laki (gambar 2 dan 3). Menurut data pada Tabel 3 dan 4, tahap percepatan pada perempuan sekitar 11 tahun $(10,75 \pm 0,886$ tahun $[C V M I 2] / 11 \pm$ 1 tahun $[M P 3-F G])$, pada laki-laki sekitar 12 tahun $(11,88 \pm 1,356$ tahun [CVMI 2] / $12 \pm$ 0,894 tahun [MP3-FG]). Fishman (1981) serta Hagg dan Taranger (1980) melaporkan bahwa tahap percepatan pertumbuhan perempuan terjadi sekitar umur 10-11 tahun sedangkan pada laki-laki sekitar umur 11-12 tahun sehingga disimpulkan bahwa tahap akselerasi pertumbuhan perempuan lebih dulu 1-2 tahun daripada laki-laki. ${ }^{3,15}$

Tahap akhir percepatan pertumbuhan yaitu CVMI 6/MP3-I perempuan dicapai 1-1,5 tahun lebih dulu dari laki-laki (Gambar 2 dan 3). Menurut data pada Tabel 3 dan 4, tahap akhir percepatan pertumbuhan perempuan sekitar 14 tahun $(14,14 \pm 1,027$ tahun [CVMI 6] / 14,11 \pm 1,079 tahun $[\overline{M P 3}-I])$, pada laki-laki sekitar $15-$ 15,5 tahun (15 tahun [CVMI 6] / 15,67 \pm 0,577 tahun [MP3-I]). Tahap akhir percepatan pertumbuhan pada subyek ini lebih cepat dibanding dengan hasil yang didapat oleh Hagg dan Taranger yaitu umur 15 tahun pada perempuan dan 17 tahun laki-laki, sedangkan pada subyek penelitian Fishman (1981) tahap akhir dicapai pada umur 16-17 pada anak perempuan dan 17-18 pada anak laki-laki. ${ }^{3,15}$

Pada Tabel 3 dan 4 juga tampak bahwa periode maturasi $M P 3-F$ sampai MP3-I dan $C V M I 1$ sampai $C V M I 6$ pada perempuan ratarata terjadi dalam rentang waktu 4 tahunan $(4,14$ tahun maturasi tulang servikal / 4,11 tahun maturasi MP3), sedangkan laki-laki 4-5 tahunan (4,6 tahun maturasi tulang servikal / 5,36 tahun maturasi MP3). Tampak bahwa bahwa rentang waktu maturasi skeletal perempuan lebih pendek dari laki-laki. Perbedaan periode maturasi skeletal perempuan dan laki-laki ini sesuai dengan yang dilaporkan Fishman, tetapi rentang waktu yang didapat Fishman lebih panjang yaitu 6 tahun untuk anak perempuan dan 6,5 tahun untuk anak laki-laki. ${ }^{15}$
Perbedaan hasil penelitian ini dengan penelitian sebelumnya kemungkinan disebabkan karena perbedaan iklim, ras dan genetik seperti pendapat Profitt bahwa waktu pubertas dipengaruhi oleh genetik dan lingkungan, ras tertentu lebih cepat dewasa dibanding yang lain. Contohnya anak Belanda usia 10 tahun lebih tinggi $5 \mathrm{~cm}$ daripada anak Amerika seusianya, anak yang tinggal di kota lebih cepat dewasa dibanding anak di desa. Profitt juga menyatakan bahwa iklim mempengaruhi rata-rata percepatan pertumbuhan. Pertumbuhan akan lebih cepat pada musim panas. Alasan lain adalah kemajuan peradaban dan nutrisi menyebabkan kecenderungan generasi terkini lebih cepat dewasa. Seperti yang terungkap dari beberapa penelitian bahwa anak-anak di akhir abad 20 lebih besar dan cepat dewasa dibanding anakanak pada awal tahun $1900 .^{15,16}$

Hasil penelitian ini mendukung penelitianpenelitian sebelumnya yang menunjukkan bahwa maturasi perempuan cenderung lebih cepat dimulai dan berakhir dibanding lakilaki. $^{3,4,15}$ Penyebab fenomena ini belum diketahui, tetapi pengaruhnya adalah perawatan ortodonsia pada anak perempuan sebaiknya dilakukan lebih dulu daripada anak laki-laki jika rencana perawatan perlu memanfaatkan percepatan pertumbuhan anak. ${ }^{16}$

Maturasi skeletal umumnya dianalisis dengan metode SMI dan CVMI kemudian beberapa peneliti mulai mengembangkan $M P 3$ sebagai indikator maturasi skeletal karena metode ini dianggap sederhana dan paparan radiasi lebih sedikit sesuai dengan prinsip radiologi diagnostik yaitu ALARA (As Low As Reasonably Achievable). ${ }^{10-13,17}$ Hasil penelitian ini menunjukkan $70,8 \%$ tahap maturasi tulang servikal sesuai dengan tahap maturasi $M P 3,9,7 \%$ tahap maturasi $M P 3$ satu tahap lebih rendah dari maturasi tulang servikal, 19,4\% tahap maturasi MP3 satu tahap lebih tinggi dari maturasi tulang servikal (Tabel 5). Kesesuaian tahap maturasi MP3 dengan tulang servikal yang tahapnya lebih tinggi atau lebih rendah kemungkinan disebabkan oleh adanya variasi biologis individual antara tahap MP3 dan tulang servikal, serta keterampilan operator dalam menginterpretasi perubahan anatomis 
tulang servikal pada foto sefalometri yang agak sulit karena bertumpang tindih dengan struktur anatomis lain. Pada aplikasi klinis, tahap maturasi MP3 dan tulang servikal memberikan informasi mengenai potensi tumbuh kembang pasien. ${ }^{9}$ Penelitian ini memperoleh kesesuaian yang cukup baik antara maturasi MP3 dengan tulang servikal yaitu $70,8 \%$, sehingga metode foto periapikal MP3 dapat dipertimbangkan sebagai alternatif dari $C V M I$ dalam menentukan maturasi skeletal.

\section{Kesimpulan}

Gambaran tahap maturasi $M P 3$ dan tulang servikal pada pasien di Klinik Ortodonsia RSGM-P FKGUI dalam rentang umur 10-16 tahun adalah sebagai berikut.

1. Pada umur kronologis yang sama, tahap maturasi MP3 dan tulang servikal yang dicapai dapat berbeda-beda dan meningkat sesuai dengan bertambahnya umur.

2. Variasi gambaran maturasi MP3 terbesar terdapat pada kelompok pasien ortodonsia anak perempuan umur 12 tahun yaitu MP3$F G$ sampai dengan $M P 3-I$ dan anak lakilaki umur 13-14 tahun yaitu $M P 3-F G$ sampai dengan $H I$.

3. Variasi gambaran maturasi tulang servikal terbesar terdapat pada kelompok pasien ortodonti anak perempuan umur 12 tahun yaitu CVMI 2 sampai dengan 5, dan anak laki-laki umur 12-13 tahun yaitu CVMI $1,2,3$ dan 5 .

4. Ada kesesuaian pola maturasi $M P 3$ tulang servikal pada pasien ortodonti umur 10-16 tahun sebesar $70,8 \%$.

\section{Daftar Acuan}

1. Fishmann LS. Chronological versus skeletal age, an evaluation of craniofacial growth. Angle Orthod 1979;49:181-9.

2. Hagg U, Taranger J. Maturation indicators and the pubertal growth spurt. Am J Orthod 1982;82:299-308.

3. Hagg U, Taranger J. Skeletal stages of the hand and wrist as indicators of the pubertal growth spurt. Acta Odontol Scand 1980;38:187-200.
4. Hunter CJ. The correlation of facial growth with body height and skeletal maturation of adolescence. Angle Orthod 1966;36:44-54.

5. Bergersen EO. The male adolescent facial growth spurt:its prediction and relation to skeletal maturation. Angle Orthod 1972;42:31938.

6. Bjork A, Helm S. Prediction of the age of maximum puberal growth in the body height. Angle Orthod 1967;37:134-43.

7. Hassel B, Farman AG. Skeletal maturation evaluation using cervical vertebrae. Am $J$ Orthod Dentofac Orthop 1995;107:58-66.

8. Kucukkeles N, Acar A, Biren S, Arun T. Comparison between cervical vertebrae and hand-wrist maturation for the assessment of skeletal maturity. J. Clin Pediatr Dent 1999;24: 47-52.

9. Gandini P, Mancini M, Andreani F. A comparison of hand-wrist bone and cervical vertebral analyses in measuring skeletal maturation. Angle Orthod 2006;76:984-9.

10. Rajagopal R, Kansal S. A comparison of modified MP3 stages and the cervical vertebrae as growth indicators. J. Clin Orthod 2002;36 :398-406.

11. Madhu S, Hedge AM, Munshi AK. The developmental stages of the middle phalanx of the third finger (MP3): a sole indicator in assessing the skeletal maturity?. J. Clin Pediatr Dent 2003;27:149-56.

12. Abdel-Kader HM. The reliability of dental $x$-ray film in assessment of MP3 stages of pubertal growth spurt. Am J Orthod Dentofac Orthop 1998;114:427-9.

13. Ozer T, Kama JD, Ozer SY. A practical method for determining pubertal growth spurt. Am J Orthod Dentofac Orthop 2006;130 :131-6.

14. Mappes, MS, Harris EF, Behrents RG. An example of regional variation in the tempos of tooth mineralization and hand-wrist ossification. Am J Orthod Dentofac Orthop 1992;101 :14551.

15. Fishman LS. Radiographic evaluation of skeletal maturation: a clinically oriented study based on hand-wrist films. Angle Orthod 1982;57 :17893.

16. Profitt WR. Contemporary Orthodontics, $3^{\text {rd }}$ ed., St. Louis, Missouri: Mosby Inc. 2000; 74,96.

17. White SC, Pharoah MJ. Oral Radiology Principles and Interpretation. $5^{\text {th }}$ ed, St. Louis, Missouri. Mosby Inc. 1004; 54. 